\title{
INTESTINAL PARASITES IN DIABETIC PATIENTS IN SOHAG UNIVERSITY HOSPITALS, EGYPT
}

\section{By}

\author{
NADA A. ELNADI ${ }^{1 *}$, HASSAN A. HASSANIEN ${ }^{2}$, AMAL M. AHMAD ${ }^{1}$ \\ AND ASMAA K. ABD ELLAH ${ }^{1}$ \\ Departments of Medical Parasitology ${ }^{1}$ and Internal Medicine ${ }^{2}$, Faculty of Medicine, \\ Sohag University, Egypt ("Correspondence: nadan295@yahoo.com)

\section{Abstract}

Intestinal parasites usually create benign diseases, though they may induce complications with high morbidity and mortality to the immunocompromised, including diabetic patients. The study detected the prevalence of intestinal parasitic infections in diabetic patients, comparing to non-diabetic controls and other parameters. A total of 100 fecal samples were collected from diabetic patients at the outpatient clinic of Sohag University Hospitals and another 100 from cross matched controls. The samples were examined macroscopically and microscopically by direct smear and different concentration methods then stained by Modified Ziehl-Neelsen Acid fast stain. Glycated hemoglobin ( $\mathrm{Hb}$ A1c) was measured to detect DM controlled patients. The data were organized, tabulated, and statistically analyzed. Intestinal parasites were found in 25 $(25 \%)$ cases out of 100 patients in diabetic group and 7(7\%) cases out of 100 controls with high significance $(\mathrm{P}<0.001))$. In the diabetic group, Giardia lamblia was detected in 22 cases $(22 \%)$ and $5(5 \%)$ among controls, Entamoeba histolytica in 7 cases (7\%) and $3(3 \%)$ among controls, Hymenolypis nana in 5 cases (5\%) and $3(3 \%)$ among controls, Entamoeba coli in 8 patients (8\%), Entamoeba hartmanni in 3 cases (3\%), Dientamoeba fragilis in a case (1\%), Cryptosporidium parvum in 5 cases (5\%) and microsporidia in 3 cases (3\%). But, E. coli, E. hartmanni, D. fragilis and C. parvum nor microsporidia were detected in controls. The rate of G.lamblia in DM patients compared to controls was high significant $(\mathrm{P}<0.001)$. Hymenolepis nana was $5 \%$ (5 cases) in diabetic patients compared to 3\% (3 cases) in controls. Residence and sex differences were not significant, while age, $>10$ years showed the highest prevalence $(\mathrm{P}<$ $0.003)$, type I infection rate was significantly higher than type II $(\mathrm{P}<0.001)$. DM control was also significantly affected the infection rates $(\mathrm{P}<0.007$ in type I and $\mathrm{P}<0.01$ in type II).

Keywords: Egypt, Diabetes mellitus, DM type I, type II, DM control, Intestinal parasites.

\section{Introduction}

Diabetes mellitus (DM) is a group of worldwide metabolic disorders characterized by hyperglycemia resulting from defects in insulin secretion, action, or both Akinbo et al (2013). The diabetes among adults in the United States ranged from $5.3 \%$ to $14 \%$ (Katon et al, 2005). Bos and Agyemang (2013) described it as an increasingly becoming a major chronic disease burden all over the world, including Egypt. The prevalence of type II diabetes ranged from $4.9 \%$ to $20.0 \%$ of the population in rural and urban areas respectively. Prasad (1999) also considered diabetics as being of immunocompromised group of patients. Although infectious intestinal parasitic diseases are uncommon to cause high morbidity or mortality to their host, yet are to be a threat to diabetic patients.

The prevalence of intestinal parasites among diabetic patients were studied in Ismailia, Egypt (Abaza et al, 1995), Turkey (Nazligul et al, 2001), Tehran, Iran (Ak0hlagi et al, 2005) and Nigeria (Akinbo et al, 2013). Magnitude of diabetes and intestinal parasitosis, urged the authors to evaluate this problem in Sohag University Hospitals as a representative of Upper Egypt.

\section{Subjects, Materials and Methods}

In the present study, 100 stool samples from diabetic patients attending the diabetes outpatient clinics of Sohag University Hospital and 100 stool samples from nondiabetic control group were collected from May to October 2013. 
Age ranged from 1-70 years $(41 \pm 20.3)$ in diabetic patients. Males were $56 \%$ and females $44 \%$ patients, while controls ranged between 1-70 years (41.7 \pm 20.2$)$, males were 54 and females 46. As regards residence, $40 \%$ urban and $60 \%$ rural areas, $25 \%$ were DM type I and $75 \%$ type II patients, $15(60 \%)$ patients of type I were controlled and $10(40 \%)$ were not, meanwhile, $50(67 \%)$ patients of type II were controlled and $25(33 \%)$ were not.

All fecal samples were preserved in formalin 10\% labeled containers, examined macroscopically and microscopically, directly (Ash and Orihel, 1991) and by simple sedimentation (Garcia, 2001) simple floatation (Markell et al, 1999), formalinethyl ether sedimentation (Garcia, 2001), Kato thick smear (Melvin and Brooke, 1983), stained with Modified ZiehlNeelsen (Henriksen and Pohlenz, 1981)
Glycated hemoglobin A1c test (HbA1c) was done in the clinic to determine the control of both types of DM as normal ranged between $4 \%$ \& $5.9 \%$ (Buse et al, 2011)

Statistical analysis: Data were tabulated, and statistically analyzed using SPSS version, 16. Chi-square test $(\chi 2)$ was used to compare frequency data. $\mathrm{P}<0.05=$ significant and $\mathrm{P}<0.001=$ highly significant.

Written signed consents were taken from all patients, controls and children's parents with their approval to undergo and publish the present data and the ethics of human rights were considered.

\section{Results}

Intestinal parasites were in $25 \%$ of diabetic group as compared to $7 \%$ in controls.

Details are given in tables $(1,2,3,4,5$ \& 6) and figure (1).

Table 2: Distribution of intestinal parasites in diabetic patients and control group.

\begin{tabular}{|c|c|c|c|c|c|c|c|c|c|c|}
\hline Parasites & \multicolumn{4}{|c|}{ Diabetic patients } & \multicolumn{4}{|c|}{ Controls } & $\mathrm{X}^{2}$ & $\mathrm{P}$ value \\
\hline & \multicolumn{2}{|c|}{ Total } & Single & Mixed & \multicolumn{2}{|c|}{ Total } & Single & Mixed & & \\
\hline G. lamblia & 22 & $22 \%$ & 7 & 15 & 5 & $5 \%$ & 1 & 4 & 10.9 & $<0.001^{*}$ \\
\hline E. histolytica & 7 & $7 \%$ & - & 7 & 3 & $3 \%$ & - & 3 & 0.94 & $<0.3$ \\
\hline E. coli & 8 & $8 \%$ & - & 8 & 3 & $3 \%$ & - & 3 & 1.5 & $<0.2$ \\
\hline E. hartmanni & 3 & $3 \%$ & - & 3 & - & - & - & - & 1.3 & $<0.2$ \\
\hline D. fragilis & 1 & $1 \%$ & - & 1 & - & - & - & - & 1 & $<0.3$ \\
\hline C. parvum & 5 & $5 \%$ & & 5 & - & - & - & - & 3.2 & $<0.07$ \\
\hline microsporidia & 3 & $3 \%$ & - & 3 & - & - & - & - & 1.3 & $<0.2$ \\
\hline H. nana & 5 & $5 \%$ & - & 5 & 3 & $3 \%$ & 1 & 2 & 0.13 & $<0.7$ \\
\hline Total patients & 25 & $25 \%$ & & & 7 & $7 \%$ & & & 10.7 & $<0.001 *$ \\
\hline
\end{tabular}

Highly significant differences $(\mathrm{p}<0.001)$ in total intestinal parasites with G. lamblia prevalent between diabetic and control groups of patients, though higher incidence in parasitic infection rates in all identified parasites ( $* \mathrm{P}<0.001$ highly significant).

Table 3: Relationship between residence of diabetic patients and intestinal parasitic infections.

\begin{tabular}{|l|c|c|c|c|c|c|}
\hline Residence(DM) & \multicolumn{2}{|c|}{ No. of tested patients \& \% } & No. of infected patients \& \% & $\mathrm{X}^{2}$ & P value \\
\hline Urban & 40 & $40 \%$ & 6 & $15 \%$ & 2.19 & $<0.1$ \\
\cline { 1 - 5 } Rural & 60 & $60 \%$ & 18 & $30 \%$ & & \\
\cline { 1 - 6 } Total & 100 & & 24 & $24 \%$ & & \\
\hline
\end{tabular}

Intestinal parasites were detected in 6 diabetic patients from urban areas $(15 \%)$ and 18 from rural ones $(30 \%)$, without significant difference $(\mathrm{P}<0.05)$.

Table 4: Comparison between incidences of intestinal parasites in type I with Type II diabetic patients.

\begin{tabular}{|c|c|c|c|c|c|c|}
\hline Type of diabetes & \multicolumn{2}{|c|}{ No. of tested patients \&\% } & \multicolumn{2}{|c|}{ No. of infected patients \&\% } & $\mathrm{x}^{2}$ & P value \\
\hline Type I & 25 & $25 \%$ & 13 & $52 \%$ & \multirow{2}{*}{11.1} & $<0.001^{*}$ \\
\hline Type II & 75 & $75 \%$ & 12 & $16 \%$ & & \\
\hline Total & 100 & $100 \%$ & 24 & $24 \%$ & & \\
\hline
\end{tabular}

Infected patients with intestinal parasites were 13 cases (52\%) with type I diabetes and 12 cases $(16 \%)$ with type II diabetes, with type I diabetic patients with a significantly high prevalence $(* \mathrm{P}<0.05)$. 
Fig. 1: Age distribution among intestinal parasites infected diabetic patients:

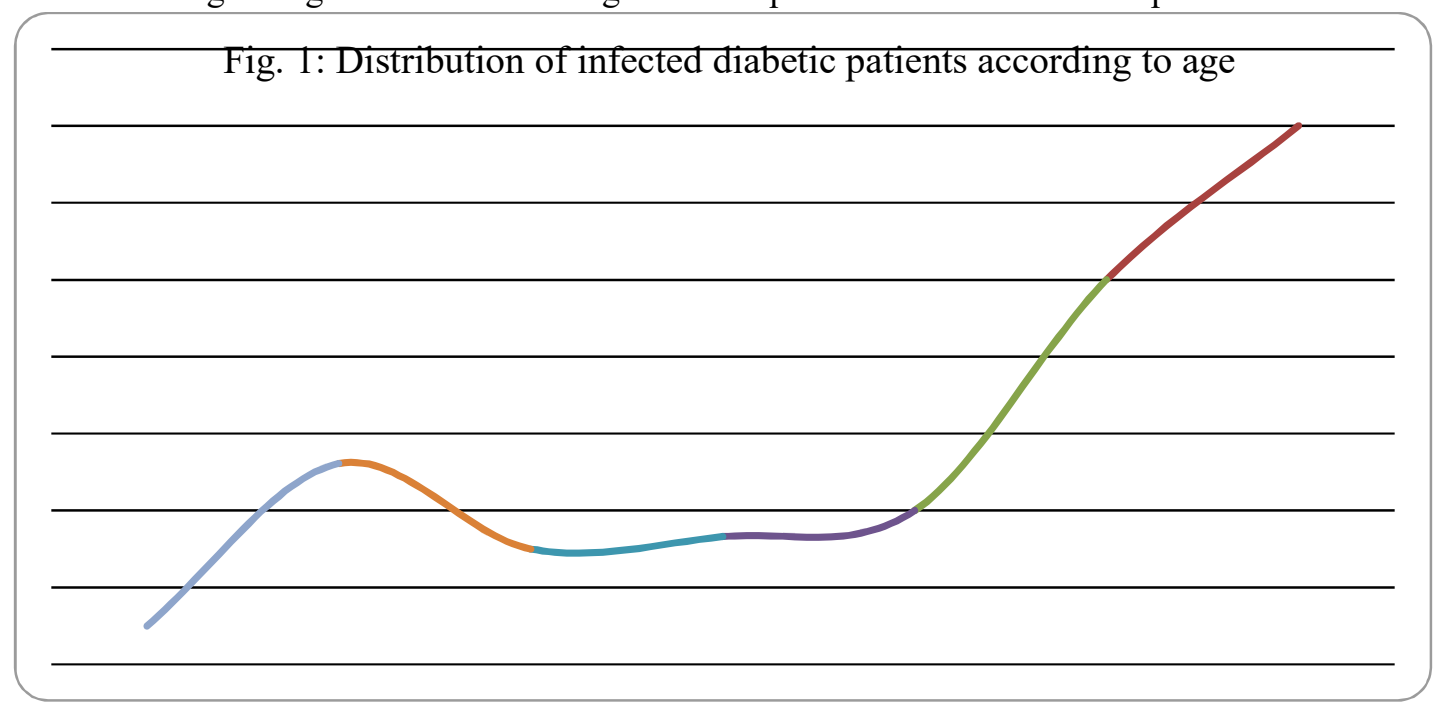

Fig. 1: Distribution of intestinal parasites in diabetic patients according to age showed high rate of infection in less than 10 years old with high significance $P<0.003, X^{2}=19.9$ ) and then gradually decreased in older ages with a gradual increased from $30 \mathrm{y}$ old to an apex between $50-59$ y old.

Table 5: Comparison between incidence of intestinal parasitic infections in controlled and uncontrolled type I diabetic patients.

\begin{tabular}{|l|c|c|c|c|c|c|}
\hline DM control & \multicolumn{2}{|c|}{ No. of tested patients \&\% } & No. of infected patients \& \% & $\mathrm{x}^{2}$ & $\mathrm{P}$ value \\
\hline Controlled type1HbA1 $<6$ & 15 & $60 \%$ & 4 & $26.6 \%$ & \multirow{2}{*}{7.2} & $<0.007$ \\
\hline Uncontrolled type1HbAb1c $>6$ & 10 & $40 \%$ & 9 & $90 \%$ & & \\
\hline Total & 25 & $25 \%$ & 13 & $52 \%$ & & \\
\hline
\end{tabular}

Infected patients with intestinal parasites were 4 cases $(26.6 \%)$ in patients with controlled type I and 10 cases (40\%) in patients with uncontrolled type I, with significant relation between intestinal parasites and control of type I diabetes $(\mathrm{P}<0.05)$

Table 6: Incidence of intestinal parasites in controlled and uncontrolled type II diabetic patients.

\begin{tabular}{|l|c|c|c|c|c|c|}
\hline DM control & \multicolumn{2}{|c|}{ No. of tested patients \&\% } & No. of infected patients \& \% & $\mathrm{x}^{2}$ & $\mathrm{P}$ value \\
\hline Controlled type II HbA1c $<6$ & 50 & $66.6 \%$ & 4 & $8 \%$ & 5.46 & $<0.01$ \\
\cline { 1 - 5 } Uncontrolled type II HbAb1c $>6$ & 25 & $33.3 \%$ & 8 & $32 \%$ & & \\
\hline Total & 75 & & 12 & $16 \%$ & & \\
\hline
\end{tabular}

Four (8\%) DM patients infected with intestinal parasites were in controlled type II and 8 $(32 \%)$ were type II uncontrolled $(\mathrm{P}<0.05)$.

\section{Discussion}

Numerous factors, in addition to directly related medical complications, contribute to the impact of diabetes on quality of life and economics. Diabetes is associated with a high affective illness (Tunceli et al, 2005) and adversely impacts employment, absenteeism, and work productivity.

In the present study, the examination of stool samples collected from the 100 diabetic patients and 100 non-diabetic controls showed the prevalence of intestinal para- sitic infections in diabetic patients $(25$ cases or $25 \%$ ) was highly significant ( $\mathrm{p}<$ 0.001 ) over only $7 \%$ (7 cases) in the nondiabetic controls.

Infection rates were lower than those found in Turkey (Nazligul et al., 2001) (47\% out of 200 diabetic patients in comparison to $55 \%$ out of 1024 healthy controls). These differences were attributed to location of the Sanliurfa Province. There, intestinal parasites were very common because of the hot climate, agricultur- 
al usage of sewage, and inadequate purified drinking water that favored spreading of zoonotic intestinal parasites.

On the other hand, the present results were more or less close to those in Iran (Akhlagi et al., 2005) where the prevalence was $15.6 \%$ out of 250 diabetic patients in comparison to $10 \%$ out of 250 of healthy controls. Abaza et al. (1995) found that the prevalence of intestinal parasitic infections in diabetic patients was $8 \%$ among 427 immunocompromised patients in Ismailia with no comparison with a control group. As they found that the diabetic group was the least group affected among different groups of immunocompromised hosts. Again, the Canal area is extremely different in its economic nature of the inhabitants (they mainly depend on trading, agricultural activities are different than used in Upper Egypt (home of this study) and they did not comment on the groups of diabetic patients recruited in the study which affects the results. Also, the present results agreed with Akinbo et al. (2013) in Nigeria reported that the prevalence of intestinal parasites as $18.7 \%$ out of 150 diabetic patients in comparison to non-diabetic controls

The present study revealed that the prevalence of intestinal parasites in diabetic patients was $30 \%$ (18/60 patients) of rural areas in comparison to $17.5 \%$ (7/40 patients) of urban ones, the residence type was of no significant effect in acquiring intestinal parasites in diabetic patients $(\mathrm{p}<$ 0.2 ).

Also, the present work showed that the prevalence of intestinal parasites was significantly related with age group as less than 10 years gave the highest prevalence $(p<0.003)$. The risk of infection in targeted group reduced with age except in ages from 50-59. Intestinal parasites were more frequently encountered during childhood as suggested by Akinbo et al. (2013) also, since hygienic habits have not been fully developed yet. However, the sudden peak noted in the number of cases of the age be- tween 50-59 years in both studies raising a question which needs more investigations to explain.

In the present study, intestinal parasites in different diabetic types were, 52\% (13/ 25 cases) in type I compared to $16 \%$ $(12 / 75$ cases $)$ with type II $(p<0.001)$. So the type of diabetes mellitus was significantly associated with intestinal parasites among diabetic patients with typel having the highest prevalence. The present results disagreed with Akinbo et al. (2013) who found that the intestinal parasites was $11.1 \%$ out of 18 patients with type 1 comparison to $19.7 \%$ out of 132 patients with type 2 without significant difference. These differences may be attributed to nature of life style in Nigeria, or efficient health care provided to Type I DM patients usually met in young children.

There was a significant association between intestinal parasites and control of type 1 diabetes $(\mathrm{p}<0.007)$. The intestinal parasites was $90 \%$ (9/10cases) uncontrolled type1 DM patients, compared to $26.6 \%$ (4/15 cases) of type1 controlled patients. Besides, in type II DM, the prevalence of intestinal parasites was $32 \%(8 / 25)$ with uncontrolled and $8 \%$ (4/50 patients) with controlled patients. So, there was a significant risk factor in case of lack of control of type II DM $(p<0.01)$. Lack of control in both types investigated in DM was proven to significantly increase the rates of intestinal parasitic infections, suggesting that the suppressed immune response in DM may be the cause (Bessman and Sapico, 1992). However, this research question is open to work in order to reach an appropriate answer.

Although G. lamblia is not an opportunistic parasite, giardiasis showed a significant value $(\mathrm{p}<0.001)$ and detected in $22 \%$ (22 cases) of diabetic patients in comparison to $5 \%$ (5cases) in controls. Akhlagi et al. (2005) in Iran reported $\backslash 9 \%$ out of 250 diabetic patients compared to $3.6 \%$ out of 250 healthy controls. The close results of 
parasitosis in both groups though low, raised the question about the source of infection, however they agreed with the present study in different occurrence even if a small one in the rate of infection in DM and control groups. Also, E. histolytica is not an opportunistic parasite, however in the present work, the prevalence of amebiasis was $7 \%$ ( 7 cases) in diabetic patients compared to $3 \%$ (3 cases) in controls, but without significant difference $(\mathrm{p}<0.3)$. Akhlaghi et al. (2005) reported $0.4 \%$ out of 250 diabetic patients compared to zero in controls.

In the present study, C. parvum was 5\% ( 5 cases) in diabetic patients compared to none in the controls, but without significant difference $(\mathrm{p}<0.07)$. Abaza et al. $(1995)$ in Ismailia detected C. parvum in $6.3 \%$ (427 immuncompromised patients) and Baiomy et al. (2010) in Cairo detected 7\% (100 immuncompromised patients) and none in the controls. These differences might be due to the fact that studies were done on different and multiple groups of immunocompromised patients and not merely confined to DM patients as the presented work.

Baqai et al. (2005) in Pakistan reported $25 \%$ of 20 diabetic patients. Their tested patients were selected from Jinnah Postgraduate Medical Centre Karachi and not from an outer clinic specialized for diabetic patients that changed the nature of patients, and they used the specific Kinyoun for parasite detection. However, Akhlaghi et al. (2005) detected the parasite in $6 \%$ out of 250 patients in diabetic patients compared to $2.45 \%$ out of 250 patients in controls as in the present results.

Microsporidial infection was detected in $3 \%$ (3 cases) in diabetic patients and none in the healthy controls but without significant difference $(\mathrm{p}<0.2)$. The present results agreed with those of Baiomy et al. (2010) who detected $2 \%$ in 100 immuno-compromised patients and none in the healthy controls, and also Abaza et al. (1995) reported
$2.3 \%$ among 427 of the immunocompromised patients.

Also, Hymenolepis nana the autoinfection cestode is not considered as an opportunistic parasite. In the present work, its prevalence was $5 \%$ (5 cases) in diabetic patients compared to $3 \%$ (3 cases) in the controls, but without significant difference $(\mathrm{p}<0.7)$. Akhlaghi et al. (2005) detected that the prevalence of $H$. nana infection was $2 \%$ out of 250 diabetic patients compared to $0.8 \%$ out of 250 patients in the healthy controls.

However, Geneidy et al. (2012) reported that the effectiveness of the pneumococcal vaccines in children decreased with the increasing in age and among patients. They added that the non-vaccinated children were at risk of Ascaris lumbricoides, Ancylostoma duodenale, Trichuris trichura, Schistosoma mansoni, S. haematobium, Wuchereria bancrofti, Enterobius vermicularis, Hymenolepis nana, Giardia lamblia, Entaemeba histolytica and Trichomonas vaginalis. Also, Agholi et al. (2013) in Iran reported that the opportunistic intestinal /parasites must be suspected in any HIV/ AIDS patient with chronic diarrhea. They added that tropical epidemic nonopportunistic enteric parasitic infections among such patients should not be neglected.

\section{Conclusion}

The outcome results showed DM was a risk factor for intestinal parasitic infections $(\mathrm{p}<0.001)$, especially G. lamblia infection $(\mathrm{p}<0.001)$. Residence and sex differences were not significant. The young aged (below 10 years old) diabetic patients were found to be at higher risk ( $p<0.003)$ along with a mysterious rise of risk at the age between 51-59 years. The risk of intestinal parasitic infections was also higher in type I diabetes $(\mathrm{p}<0.001)$ than type II. Control of DM significantly $(p<0.007$ in type I and in type II affected the prevalence of intestinal parasites $(\mathrm{p}<0.01)$.

So, DM is a threatening health condition for intestinal parasites especially among 
young, type I uncontrolled patients. The treatment of these intestinal parasites is a must to minimize the diabetic complications.

\section{References}

Abaza SM, Makhlouf LM, el-Shewy KA, elMoamly AA, 1995: Intestinal opportunistic parasites among different groups of immunocompromised hosts. J. Egypt. Soc. Parasitol. 25, 3:713-27.

Agholi, M, Hatam, GR, Motazedian, MH, 2013: HIV/AIDS-associated associated opportunistic protozoal diarrhea. AIDS Res. Hum. Retroviruses 29, 1:35-41.

Akhlaghi, L, Gharavi, MJ, Faghihi, AH, Jabbari. M, 2005: Survey on the prevalence rates of intestinal parasites in diabetic patients in Karaj and Savodjbolagh Cities. R.J.M.S. 12, 45:23-9.

Akinbo, FO, Olujobi, SO, Omoregie, AR, Egbe, C, 2013: Intestinal parasitic infections among diabetes mellitus patients. Biomark. Genom. Med. 5, 1: 44-7.

Ash, L, Orihel, T, 1991: Parasites: a Guide to Laboratory Procedures and Identification. ASCP Press, Chicago.

Baiomy, AM, Mohamed, KA, Ghannam, M A, Shahat. SA, Al-Saadawy, AS, 2010: Opportunistic parasitic infections among immunocompromised Egyptian patients. J. Egypt. Soc. Parasitol. 40, 3: 797-808.

Baqai, R, Anwar, S, Kazmi, SU, 2005: Detection of Cryptosporidium in immunosuppressed patients. Med. Coll. Abbottabad. 17, 3:38-40.

Bessman, AN, Sapico, FL, 1992: Infections in the diabetic patient: the role of immune dysfunction and pathogen virulence factors. J. Diabetes Compl. 6:258-62.
Bos, M, Agyemang, C, 2013: Prevalence and complications of diabetes mellitus in Northern Africa, a systematic review. BMC. Pub. Hlth. 25, 13:387-92.

Buse JB, Polonsky KS, Burant CF, 2011: Type 2 diabetes mellitus. In: Melmed S, Polonsky KS, Larsen PR, et al, eds. Williams Textbook of Endocrinology. $12^{\text {th }}$ ed. Philadelphia, PA: Elsevier Saunders.

Garcia, LS, 2001: Diagnostic Medical Parasitology, 4th ed. Washington, D.C.: A.S.M. Press.

Geneidy, MR, El-Dahshan, TA, Metwally, K M, 2012: Opportunistic parasites in children with pneumococcal infection in greater Cairo, Egypt. J. Egypt. Soc. Parasitol. 42, 3:753-60.

Henriksen, SA, Pohlenz, JFL, 1981: Staining Cryptosporidia by Modified Ziehl Neelsen technique. Acta Vet. Scand. 22:594-6.

Katon, WJ, Rutter, C, Simon, G, et al, 2005: The association of comorbid depression with mortality in patients with type 2 diabetes. Diabetes Care 28:2668-76.

Markell, EK, John, DT, Krotoski, WA, 1999: Lumen-Dwelling Protozoa. In: Markell and Voge's Medical Parasitology $8^{\text {th }}$ ed. Philadelphia, P.A.: W. B. Saunders Co.

Melvin, DM, Brooke, MM, 1985: Laboratory Procedures for the Diagnosis of Intestinal Parasites, U.S. of Department Health, Education, and Welfare publication. Washington, D.C. Government Printing Office.

Nazligul, Y, Tevfik, S, Hatice, O, 2001: Is there a predisposition to intestinal parasitosis in diabetic patients? Diabetes Care 24, 8:1503-4. Prasad, CE, 1999: Immunodeficiencies in diabetes and mycobacterial infections. Int. J. Diabetes Dev. Countries 19:52-5.

Tunceli, K, Bradley, CJ, Nerenz, D, et al, 2005: Impact of diabetes on employment and work productivity. Diabetes Care 28:2662-9 


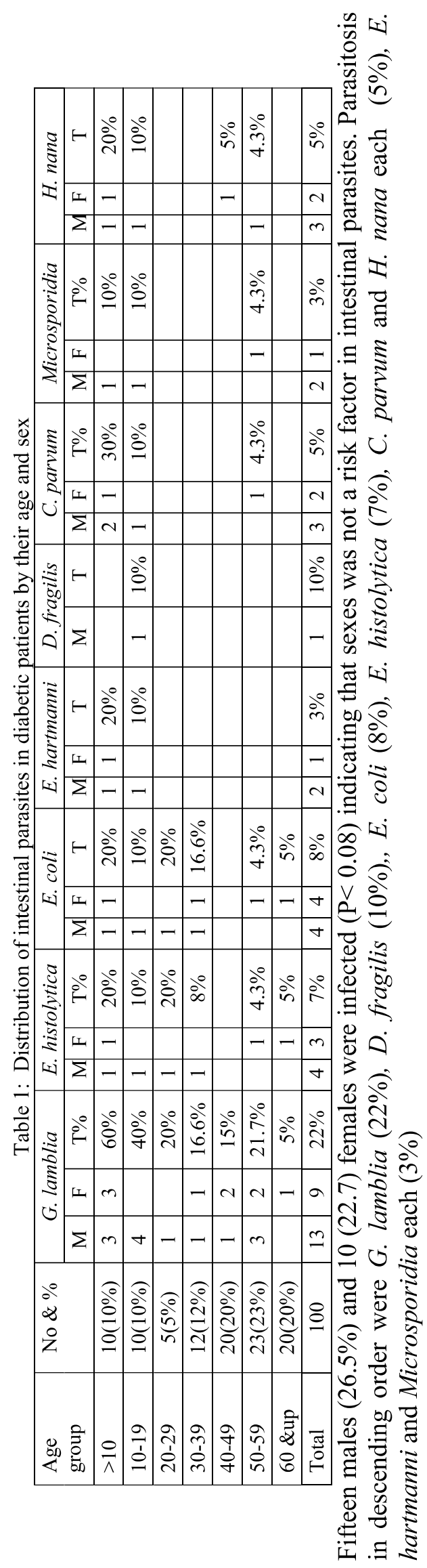

夺 